\title{
KARTAGENER SYNDROME: A CASE REPORT
}

\author{
SAMANE NAJAFI ${ }^{1}$, ALI MOHAMMADPOUR ${ }^{2}$, MARYAM ESHGHIZADEH ${ }^{3 *}$
}

${ }^{1}$ Department of Family Health, Social Development and Health Promotion Research Center, Gonabad University of Medical Sciences, Gonabad, Iran. ${ }^{2}$ Department of Medical-Surgical Nursing, Faculty of Nursing and Midwifery, Social Determinants of Health Research Center, Gonabad University of Medical Sciences, Gonabad, Iran. ${ }^{3}$ Department of Medical-Surgical Nursing, Social Development and Health Promotion Research Center, Gonabad University of Medical Sciences, Gonabad, Iran. Email: m.eshghizadeh@yahoo.com

Received: 03 March 2018, Revised and Accepted: 28 March 2018

\section{ABSTRACT}

Kartagener syndrome is a rare genetic disorder which includes a triad of bronchiectasis, chronic sinusitis, and situs inversus. Primary ciliary dyskinesia (PCD) can be one of the causes of the above symptoms in this syndrome. This study aims to contribute toward a greater understanding of Kartagener syndrome by reporting a rare case. This 16-year-old boy was hospitalized in the internal ward of 22 Bahman Hospital in Gonabad on February 23, 2016 and presented with suspected Kartagener syndrome and PCD, whose diagnosis of Kartagener syndrome and PCD was confirmed according to biopsy of the nose and antitrypsin test. The patient also underwent electrocardiography, chest X-ray, pelvic and abdominal ultrasound, and computed tomography scan with high resolution and no contrast of the chest, abdomen, and sinuses. As a rare disorder, Kartagener syndrome should be borne in mind in differential diagnoses of chronic respiratory infections and must be diagnosed as early as possible to improve patient's quality of life.

Keywords: Kartagener syndrome, Primary ciliary dyskinesia, Situs inversus, Dextrocardia.

(C) 2018 The Authors. Published by Innovare Academic Sciences Pvt Ltd. This is an open access article under the CC BY license (http://creativecommons. org/licenses/by/4. 0/) DOI: http://dx.doi.org/10.22159/ajpcr.2018.v11i5.25593

\section{INTRODUCTION}

Kartagener syndrome was first reported by Siewert (1904) and Gunter (1923) with symptoms of bronchiectasis and situs inversus. In 1933, Kartagener proposed a triad of symptoms of situs inversus, chronic sinusitis, and bronchiectasis [1-3]. In America, the prevalence of this genetic disorder has been reported 1/32,000 live births [4]. Abnormalities such as primary ciliary dyskinesia (PCD) can be one of the main causes of the above symptoms in Kartagener syndrome. Kartagener syndrome is less prevalent than PCD [5]. Frequent pneumonia accompanied with bronchiectasis are common in these patients, for which, immotile embryonic ciliary is a possible cause [6]. PCD is a rare hereditary defect that is predominantly inherited in autosomal recessive form. The presence of PCD in Kartagener syndrome causes progressive symptoms and malfunction in sinuses and lung [7-9]. The prevalence of PCD varies from $1 / 20,000$ to $1 / 60,000$ live births, of whom, 50\% may randomly develop situs inversus [5].

The left and right sides of the body are determined once development process is initiated, and their formation is coordinated by a cascade of genes. The natural positioning of organs inside the body is referred to as situs solitus (spleen and stomach on the right, the liver on the left, right atrium on the right and the left one on the left, and the lung's triangular lobe on the right), and inversed positioning of abdominal and thoracic organs is referred to as situs inversus, and positioning of heart on the right (dextrocardia) is called situs totalis. With a prevalence of $1 / 7000$ births, situs inversus is a rare and non-pathological status in which abdominal and thoracic viscera are misplaced. Situs inversus has a prevalence of 1/4000-8000 births in China. Despite such misplacements of organs, the prevalence of other structural abnormalities in these patients is only slightly higher compared to normal people and usually associated with normal physiology. However, the likelihood of heart defects can be slightly higher in people with situs inversus. The prevalence of congenital cardiac abnormalities, accompanied by situs inversus has been reported 3-5\% [10].

\section{CASE REPORT}

The patient, a 16-year-old single male student, living in Gonabad city, presented with a fever of $40^{\circ} \mathrm{C}$, dyspnea, coughing, and pneumonia and was hospitalized in the internal ward of 22 Bahman Hospital in Gonabad on February 23, 2016. He reported a history of frequent sinusitis and pneumonia in early life and no family history of heart or respiratory diseases. His parents were not related, and his mother had no particular problem during pregnancy. About a week before admission, the patient had not responded to treatment initiated with ceftriaxone and azithromycin. At admission, the patient had a regular pulse rate of $87 / \mathrm{min}$, blood pressure of $120 / 80 \mathrm{mmHg}$, and a respiratory rate of $22 /$ min. On auscultation of the lung, the patient had soft crackling sound, generalized rhonchi on the left accompanied by a wheezing sound, and complained about pleuritic pain. On examination of the heart, heart apex beat was seen in the $6^{\text {th }}$ intercostal space on the right, and heart sounds (S1 and S2) in the right side of the thorax. Table 1 presents some of the patient's clinical symptoms and laboratory results. According to clinical symptoms and paraclinical results such as triad of Kartagener and positive saccharin and antitrypsin tests, diagnosis of Kartagener syndrome and PCD was confirmed in the patient. Treatment was initiated for the patient with bronchodilator and mucolytic drugs and antibiotics such as clindamycin, cefepime, and amikacin. The patient also underwent electrocardiography (Fig. 1), chest X-ray (Fig. 2), pelvic and abdominal ultrasound, and computed tomography (CT) scan with high resolution and no contrast of the chest (Fig. 3), abdomen (Fig. 4), and sinuses (Fig. 5).

The patient was discharged fully recovered after 10 days of treatment with above antibiotics. Considering patient's history of frequent pneumonia and sinusitis, and bronchiectasis and evidence of situs inversus totalis (which are two main components of the triad of Kartagener syndrome that could also be due to PCD), the patient was referred to specialist clinics for definitive diagnosis of Kartagener syndrome and PCD and further follow-up. Given the previous medical history and following specialty tests (biopsy of the nose and antitrypsin test), the patient was definitively diagnosed with Kartagener syndrome and PCD.

\section{DISCUSSION}

Kartagener syndrome and PCD are among rare disorders in men, associated with bronchiectasis, sinusitis, situs inversus, and infertility, which can be attributed to abnormal ciliary motility. Affected patients 


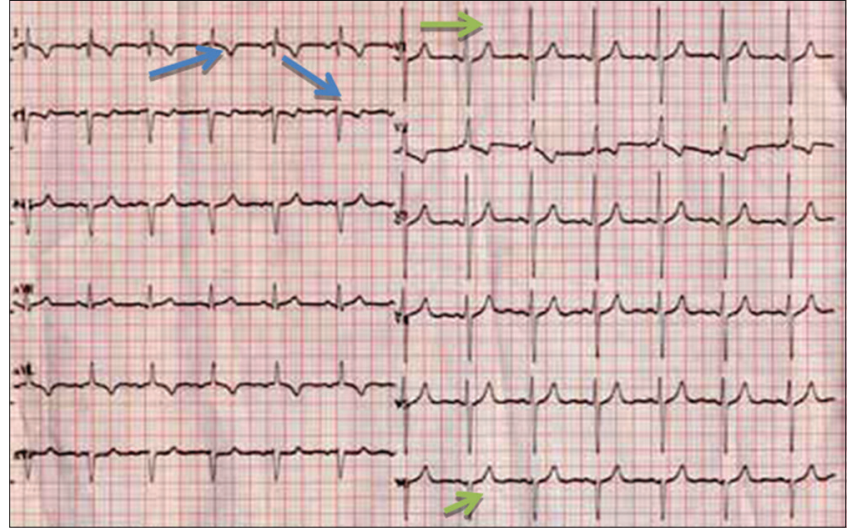

Fig. 1: Electrocardiography showing negative $P$ in Leads I and II (blue arrows), poor R progression in V1 to V6 leads, long R wave in $\mathrm{V} 1$, and no $\mathrm{R}$ wave in $\mathrm{V} 6$ (green arrows)

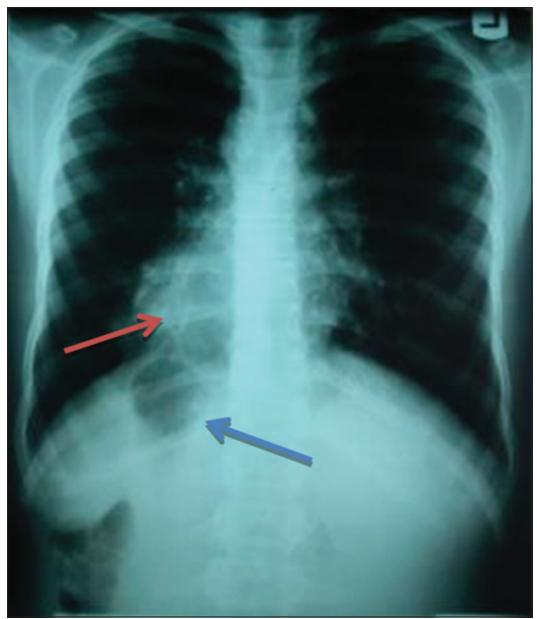

Fig. 2: Chest and upper abdomen radiography showing dextrocardia and heart apex and aortic arch on the right (red arrow), lung infiltration and stomach bulb under the right diaphragm (blue arrow)

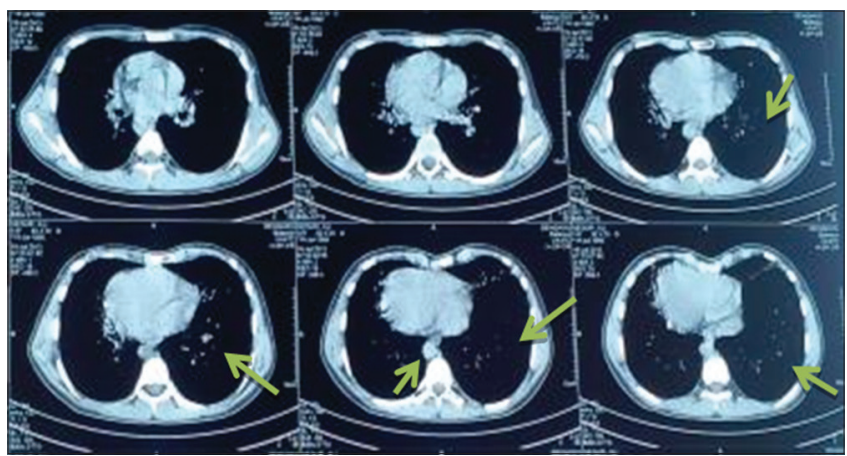

Fig. 3: Chest computed tomography scan showing some degree of bronchiectasis, hyperinflation, and bilateral infiltration (green arrows)

suffer from ineffective mucociliary clearance due to ciliary dysfunction in the upper and lower airways [11]. We investigated the case of a patient with Kartagener syndrome and PCD.

Chronic infections of the upper respiratory system such as sinusitis, rhinosinusitis, and otitis, and also of the lower respiratory system such as bronchiectasis or frequent pneumonia are particularly important. PCD disorder should be borne in mind with clinical symptoms of the

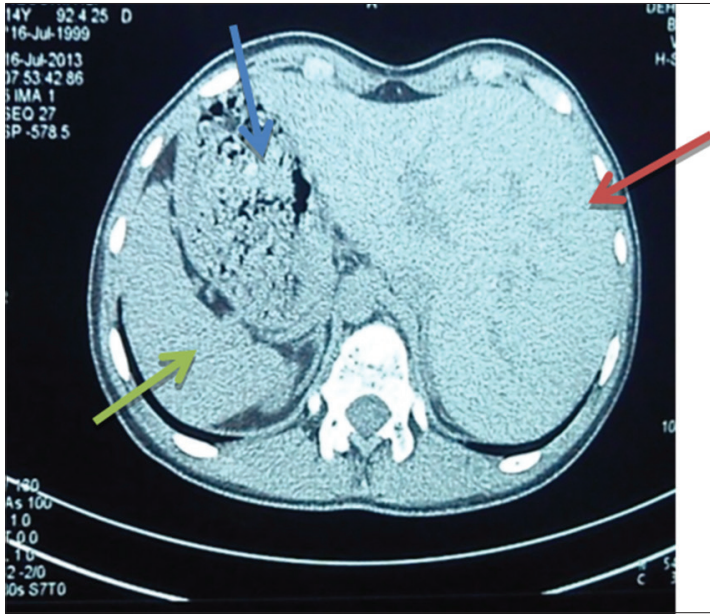

Fig. 4: Computed tomography scan of the abdomen showing liver on the left (red arrow), and stomach (blue arrow), and spleen (green arrow) on the right

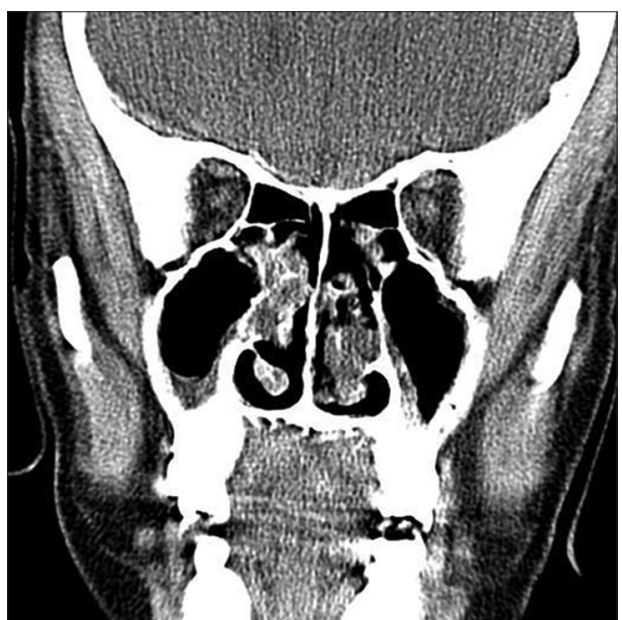

Fig. 5: Computed tomography scan of sinuses showing sinusitis

lung and sinuses including pneumonia, sinusitis, and bronchiectasis, and Kartagener syndrome (a rare case) should be considered likely when these symptoms concur with situs inversus [2]. In the present study, situs inversus (one of the triad of components of Kartagener syndrome) was found in the patient. Plain radiography and CT scan of the abdomen and thorax can help diagnose situs inversus [12]. In the case of this patient, clinical symptoms and evidence based on such methods proposed a definitive diagnosis of situs inversus totalis.

Currently, electron microscope is the gold standard for diagnosis of PCD and Kartagener syndrome. Other diagnostic methods including clinical results such as situs inversus and dextrocardia, involve saccharin clearance test, and semen analysis in males [13]. In saccharin clearance test, PCD is suspected if nasal mucociliary takes longer than $60 \mathrm{~min}$ to clear. In electron microscope method, nasal cilia are examined in a biopsy taken from nasal or bronchial mucosa, and diagnosis is confirmed in the absence of inner and outer dynein arms [14]. Definitive diagnosis of Kartagener syndrome and PCD was proposed according to test results. Of all the usual techniques, only semen analysis test was not performed due to patient's age.

As a genetic disease, Kartagener syndrome and PCD have no definite treatment. Treatment of patients is symptomatic and includes intermittent or constant oral or intravenous administration of antibiotics to treat respiratory infections. Bronchiectasis and pneumonia should be treated with inhaling bronchodilators, mucolytics, oral corticosteroids, and chest physiotherapy. Since Haemophilus 
Table 1: Clinical symptoms and para-clinical results in patient with Kartagener syndrome

\begin{tabular}{ll}
\hline Signs and symptoms & Clinical and laboratory results \\
\hline Otitis media & Negative \\
Sinusitis & Positive \\
Finger clubbing & Negative \\
Dextrocardia (chest X-ray) & Positive \\
Situs inversus & Positive \\
(CT scan and ultrasound) & \\
Bronchiectasis (HRCT) & Positive \\
Thyroid function test & Normal \\
Renal function test & Normal \\
Liver function test & Normal \\
BCG test & Negative \\
Agglutination test wright & Negative \\
2 ME test & Negative \\
Hemoglobin & 13.5 mg/dl \\
White blood cells & 17500 \\
ESR after $1^{\text {st }}$ h & 19 \\
ESR after $2^{\text {nd }}$ h & 44 \\
Saccharin clearance test & NMC>60 min \\
ANA & Normal \\
IgA & 110 \\
IgG & 1400 \\
IgM & 150 \\
IgE & 12 \\
Antitrypsin & $285(143-240)$ \\
Perspiration test & Negative \\
PND & Positive \\
\hline
\end{tabular}

CT: Computed tomography, HRCT: High resolution computed tomography, BCG: Bacillus Calmette-Guérin, PND: Postnasal drip, NMC: Nasal mucociliary clearance, ESR: Erythrocyte sedimentation rate

influenza and Staphylococcus aureus are the most common infectious agents, administration of influenza and pneumococcus vaccines is also necessary to prevent frequent infections. In patients with medically incurable chronic sinusitis, endoscopic sinus surgery for transient improvement of symptoms of the upper and lower respiratory system is recommended [13]. Taiana et al. reported successful pulmonary surgery in a 25-year-old man, which involved lower left lobectomy, lingulectomy and partial excision of the left upper anterior lobe of the lung $[15,16]$. Lung together with heart transplantations have also been successful in more critical cases [17-19].

\section{CONCLUSION}

It may be concluded that recognition of less prevalent but important diseases such as Kartagener syndrome and PCD should be part of the differential diagnosis of patients with chronic infections of the respiratory system. Appropriate and early treatment and care of these patients can enhance their quality of life, improve prognosis, and prevent the progress of respiratory problems such as pneumonia and bronchiectasis.

\section{ACKNOWLEDGMENTS}

Authors wish to express their thanks to the deputies or treatment, and Research and Technology of Gonabad University of Medical Sciences, and personnel of internal and Emergency Departments of 22 Bahman Hospital in Gonabad. Authors also especially thank the patient and his family for their cooperation in preparing this report.

\section{AUTHOR'S CONTRIBUTION}

The conception and design of the study: Samane Najafi. Acquisition and analysis of data: Samane Najafi, Ali Mohammadpour. Drafting the article or revising it critically for important intellectual content: Samane Najafi, Ali Mohammadpour, Maryam Eshghizadeh. Final approval of the version to be submitted: Samane Najafi, Ali Mohammadpour, Maryam Eshghizadeh.

\section{CONFLICTS OF INTEREST}

The authors have no conflicts of interest.

\section{REFERENCES}

1. Kartagener M. Zur pathogenese der bronchiectasien. I Mitteilung: Bronchiectasien bei situs viscerum inversus. Betr Klin Tuberk 1933;83:498-501.

2. Bent JP, Smith RJ. Intraoperative diagnosis of primary ciliary dyskinesia. Otolaryngol Head Neck Surg 1997;116:64-7.

3. Siraj F1, Hussain MM, Showkat HI, Sarmast AH, Dar NA, Bhat GM. Photoclinic. Kartagener's syndrome. Arch Iran Med 2013;16:129-30.

4. Chuhwak EK. Kartagener syndrome in a Nigerian African, a case report and literature review. Niger J Med 2009;18:424-7.

5. Olbrich H, Haffnex K, Kispert A, Volkel A, Volz A, Sasmaz G, et al. Mutation in DNA H5 cause primary cilliary dyskinesia and randomization of left right asymmetry. Nat Genet 2002;30:143-4.

6. Chernick V, Boat TF, Wilmott RW, Bush A. Kendig's Disorders of the Respiratory Tract in Children. $7^{\text {th }}$ ed. Philadelphia, PA: Saunders- Elsevier; 2006. p. 485-90.

7. Afzelius BA, Eliasson R. Male and female infertility problems in the immotile-cilia syndrome. Eur J Respir Dis Suppl 1983;127:144-7.

8. Bartoloni L, Blouin JL, Pan Y, Gehrig C, Maiti AK, Scamuffa N, et al. Mutations in the DNAH11 (axonemal heavy chain dynein type 11) gene cause one form of situs inversus totalis and most likely primary ciliary dyskinesia. Proc Natl Acad Sci 2002;99:10282-6.

9. Biggart E, Pritchard K, Wilson R, Bush A. Primary ciliary dyskinesia syndrome associated with abnormal ciliary orientation in infants. Eur Respir J 2001; 17:444-8.

10. Paschala A, Koufakis T. Looking in the mirror: Situs inversus totalis. Pan Afr Med J 2015;20:87.

11. Camner P, Mossberg B, Afzelius BA. Evidence of congenitally nonfunctioning cilia in the tracheobronchial tract in two subjects. Am Rev Respir Dis 1975;112:807-9.

12. Toledo MF, Adde FV. Primary ciliary dyskinesia in children. J Pediatr (Rio de J) 2000;76:9-16

13. Gupta S, Handa K, Kasliwal R, Bajpai P. A case of Kartagener's syndrome: Importance of early diagnosis and treatment. Indian J Hum Genet 2012;18:263-7.

14. Corbo GM, Foresi A, Bonfitto P, Mugnano A, Agabiti N, Cole PJ. Measurement of nasal mucociliary clearance. Arch Dis Child 1989;64:546-50.

15. Taiana JA, Villegas AH, Schieppati E. Kartagener's syndrome: Report of a case treated by pulmonary resection; Review of the literature. J Thorac Surg 1955;30:34-43.

16. Otgün I, Karnak I, Tanyel FC, Senocak ME, Büyükpamukçu N. Surgical treatment of bronchiectasis in children. J Pediatr Surg 2004;39:1532-6.

17. Shyama K, Prudence AR. Improving antibiotic prescribing pattern and assessment of co-morbidities associated with respiratory tract infections. Int J Pharm Pharm Sci 2017;9:283-6.

18. Alvarez A, Algar FJ, Santos F, Lama R, Baamonde C, Cerezo F, et al. Pediatric lung transplantation. Transplant Proc 2005;37:1519-22.

19. Rajendran R, Balan R, Ganesan N, Thiruvengadam D. Recent modalities in drug delivery via inhalation therapy-an advanced treatment strategy for pulmonary carcinoma. Int J Pharm Pharm Sci $2015 ; 7: 8-21$ 